\title{
Crop Science
}

Ph. D.

\section{Substitution of Wheat Flour by Local Cereals and Pulses Flour An Approach to Overcome Wheat Gap in Egypt}

\section{Zeinnab Raafat Atia}

The recent study was carried out with the following objective; 1) determine the possibility of substituting local wheat varieties flour with naked rice, sorghum and barley flours in relation to proximate composition and rheological properties.2) Reaching the optimum mixing ratio for local pulses represented by Fenugreek flour and soybean flour that enhance the substitution of local non wheat cereals in bread making.. Crude protein percentage were significantly $(\mathrm{p} \geq 0.01)$ different among the studied cultivars. In the meantime, the studied flour blends were significantly $(\mathrm{p} \geq 0.01)$ different in all studied chemical analysis characters. Also, significant $(\mathrm{p} \geq 0.01)$ interaction between varieties and flour blends were reached in crude protein percentage. Over the studied wheat cultivars, gluten content of the different flour blends were significantly lower than the recorded value for wheat flour $(8.111 \%)$. Substitution with $10 \%$ rice flour gave significantly lower gluten percentage (7.493\%). Additional substitution with any of fenugreek or soybean flour, although, showed lower dry gluten percentage, that reduction had not reached the level of significance $(7.20$ and $7.339 \%$ for $10 \%$ rice flour $+5 \%$ fenugreek flour and $10 \%$ rice flour $+5 \%$ soybean flour substitution, respectively). Blends with $10 \%$ barley flour had lower values of falling number over these containing $20 \%$ barley flour by $21.67(\mathrm{P} \geq 0.0001)$, $19.84(\mathrm{P} \geq 0.0001)$, and $16.06(\mathrm{P} \geq 0.0001)$ Sec. for Misr 2, Giza171 and Gimmeza17, respectively. Rice flour blending to wheat flour at $10 \%$ level, significantly gave broader loaf diameter $(20.67 \mathrm{vs} .21 .04 \mathrm{~cm}$ for wheat flour and wheat flour $+10 \%$ rice flour, respectively).

Advisors Committee

Prof. Dr. MosaadM.El-Ganbeehy

Prof. Dr. Mohammed Abd EL-Sattar Ahmed
Examiners Committee

Prof. Dr. Mohamed M.Abdalla Elashry

Prof. Dr. Shaaban Ahmed El-Shamarka

Prof. Dr. MosaadM.El-Ganbeehy

Prof. Dr. Mohammed Abd EL-Sattar Ahmed

\section{Sc.}

\section{Management of Johnson Grass "Sorghum halepense, L" As a New Forage Crop in Egypt}

\section{Koon Aban Deng}

In many countries of the world, Sorghum forage is the basic feed for livestock. The main objectives of the recent study are; 1) evaluate the response of Alleppo grass to sowing methods and seeding rates, 2) define the optimum cutting and stubble height for efficient Johnson grass forage and determine the efficient nitrogen dose and form for Johnson grass production. Green forage yield was significantly $(\mathrm{P} \geq 0.05)$ varied with cuttings. Neither seeding rates nor sowing methods had any significant effects on green forage yield. Also, the first and the second order interactions between seeding rates, sowing methods and cutting had not reached the level of significance. The insignificant effects of both seeding rates, sowing method and their interaction might drive the conclusion that, $8 \mathrm{~kg}$. faddan ${ }^{-1}$ and the simplest sowing method, broadcasting are suitable for Johnson grass cultivation. In the meantime, the slow growth rate of Johnson grass and the very limited green forage potentiality that was expressed by diminished total green forage yield might indicate that, Johnson grass is less competitive to the privielling forage crops in the Egyptian forage rotation of North Delta region. Over sowing methods, about 9-10 ton.faddan ${ }^{-1}$ of dry forage were obtained across seeding rates.

\author{
Advisors Committee \\ Prof. Dr. Mohammed Abd EL-Sattar Ahmed. \\ Dr. Asmmaa M. Samir Rady
}

\section{Examiners Committee}

Prof.Dr.kadria MahmoudElsayed

Prof. Dr.Mahmoud El-Desouky Ibrahim

Prof.Dr. MohammedAbd El-SattarAhmed 


\section{Floriculture and Ornamental Plants}

Ph. D.

\section{Phytoremediation of Polluted Soil Using Some Ornamental Trees}

\section{Radwa Mohamed Abd El-Azim}

This experiment was conducted at the Nursery of the Department of Floriculture, Ornamental Horticulture and landscape Gardening - Faculty of Agriculture Shatby - University of Alexandria in two successive seasons (2014-2015 and 2015-2016), to study the biological treatment of contaminated soil with some heavy metals using some trees, namely;

1. Acacia saligna (inoculated with Rhizobium sp.,).

2. Casuarina glauca: which inoculated with Frankia.

The treatments of the heavy metals $(\mathrm{Cd}-\mathrm{Zn}-\mathrm{Pb})$ were: Control - $250-500$ and $1000 \mathrm{mg} / \mathrm{kg}$ soil. The most important results follows:

- The application of the high level of heavy metal (500- $1000 \mathrm{ppm})$ lead to decrease the growth parameters in both seedlings. The negative effect of the pollutant was more significant in uninoculated seedlings with Rhizobium and Frankia.

- Both of $\mathrm{Cd}$ and $\mathrm{Pb}$ had harmful impact on plant growth than that the $\mathrm{Zn}$ did. On the other hand, the effect of the $\mathrm{Zn}$ content was more harmful on $\mathrm{C}$. glauca seedlings.

- Chlorophyll contents of the phyllodes were decreased as a result of application of heavy metal.

- The inoculated plants with Rhizobium and Frankia had displayed a significant increase in carotine content under high levels of heavy metals as it compared with uninoculated ones.

- Nitrogen and phosphorus contents were decreased in the phyllodes of inoculated seedlings with Rhizobium and branchlets of Frankia with increasing of heavy metal level.

- The concentration of lead in the phyllodes was higher than that detected in the roots, particularly in uninoculated seedlings with Rhizobium, while for the Casuarina seedlings, both of $\mathrm{Pb}$ and $\mathrm{Zn}$ in the roots was higher than that in the leaves.

\section{Advisors Committee}

Prof. Dr. Tarek Mahmoud El-kiey

Prof. Dr. Ahmed A. A. El-Settawy
Examiners Committee

Prof. Dr. Emam Mohamed Saber Nofal

Prof. Dr. Essam Abd El-Rahman Koreish

M. Sc.

\section{Effect of Organic and Mineral Fertilization on The Yield ond Oil Quality of Rosemary (Rosmarinus officinalis L.)}

\section{Sherif Mahmoud Mohamed El-Gebaly}

This study had been conducted at the Experimental Research Station of the Faculty of Agriculture, Shatby, Alexandria University, during the two successive seasons of 2016/17 \& 2017/18. The mineral fertilizer (NPK) was used at the percentage of (20:5:5) at four levels which were $0,100,200$ and $300 \mathrm{Kg}$./fed./season, and the organic fertilizer was the cattle manure (CM) which used at five rates which were $0,20,30,40$ and $50 \mathrm{~m} 3 / \mathrm{fed}$./season, as well as the interaction between them. For the traditional cultivation system we recommend to fertilize rosemary plants with $300 \mathrm{Kg}$. NPK/fed. with $50 \mathrm{~m} 3 \mathrm{CM} /$ fed. or $200 \mathrm{Kg}$. NPK/fed. with $50 \mathrm{~m}_{3} \mathrm{CM} / \mathrm{fed}$. for the best vegetative growth and oil yield and chemical composition.

\author{
Advisors Committee \\ Prof. Dr: Mohamed Awad Al-Eryan \\ (Principal supervisor) \\ Dr: Amany Mostafa Abu-Shall \\ Dr: Hanaa Saleh Hussein
}

\author{
Examiners Committee \\ Prof. Dr. Mohamed Abd Elkader El-aw \\ Prof. Dr. Hanan Mohamed Ramadan \\ Prof. Dr: Mohamed Awad Al-Eryan \\ (Principal supervisor) \\ Dr: Amany Mostafa Abu-Shall
}


Ph. D.

\title{
Micropropagation and in Vitro Mutagenesis of Cordyline terminals "Red Top"
}

\author{
Heba Mohammad El-Said El-Sammak
}

\begin{abstract}
Due to the slow, expensive and time - consumed conventional propagation of Cordyline, and the merits of in vitro propagation for overcoming on these problems. The present study was undertaken. Simple protocol for in vitro regeneration of Cordyline terminalis cv. Red Top using shoot tip explants was achieved. For initiation stage, shoot tip explants were cultured on MS medium fortified with both 3\% sucrose (w/v) and $0.2 \%$ gelrite $(\mathrm{w} / \mathrm{v})$. As for multiplication stage, the new formed axillary shoots were cultured on MS fortified with various concentrations of benzyladenine (BA; 0, 1, 3, 5 and $7 \mathrm{mg} / \mathrm{l}$ ) and thidiazuron (TDZ; 0, 0.5, 1, 1.5 and $2 \mathrm{mg} / \mathrm{l}$ ) in the presence of $1 \mathrm{mg} / \mathrm{l} \mathrm{Kinetin}$ (Kin) were used. As for shoot elongation and in vitro rooting stage, new formed shoots derived from multiplication stage were culture on MS- PGRs -free medium gelled with $2 \%(\mathrm{w} / \mathrm{v})$ gelrite. Concerning the acclimatization stage, the rhizogened plantlets were potted in mixture media consists of peat moss and vermiculite $(1: 1 \%)$. The survival percentage of new formed plantlets after acclimatization was $100 \%$ of the treatments; $1 \mathrm{mg} / \mathrm{l} \mathrm{BAP}+1 \mathrm{mg} / \mathrm{K} \mathrm{Kin}, 7 \mathrm{mg} / \mathrm{l} \mathrm{BAP}+1 \mathrm{mg} / \mathrm{l} \mathrm{Kin}$ and $1.5 \mathrm{mg} / 1$ TDZ $+1 \mathrm{mg} / 1 \mathrm{Kin}$ under the light intensity $30 \mu \mathrm{mol} \mathrm{m} \mathrm{m}^{-2} \mathrm{~s}^{-1}$. The procedure outlined has fulfilled the requirements for micropropagation of Cordyline. Randomly amplified polymorphic DNA (RAPD) analysis showed that the polymorphism level was the same at all primers $(100 \%)$.
\end{abstract}

Examiner's committee:

Fardous Abd El-Salam Minisi

Aly Ibrahim Aly Abido

Mohammed Gamal El-Torky

Mohamed El-Sayed Mohamed El-Mahrouk

\author{
Advisors' Committee: \\ Mohammed Gamal El-Torky \\ Hoda El-Sayed Elmokadem \\ Mohamed El-Sayed Mohamed El-Mahrouk
}

\section{Applied Entomology \&Zoology}

\section{Ph. D.}

\section{Producing Strong Honey Bee Colonies by Using Some New Techniques Shaimaa Nagy Mostafa}

Multiple honey bee queen colonies contained two to four mated queens which able to move freely were produced by ablation of half to two thirds of mandibles of queens which trigger fighting and queen elimination within the colony. This method showed the high success techniques, 74 out of 81 queens $(91.3 \%)$ were accepted after their introduction in Carniolan, Italian and Carniolan hybrid colonies. The success ratio scored $100 \%$ in single queen colonies as control.

The multiple queen colonies are sustainable enough for long term without losing any queen from the spring to next summer in the second year. The multiple queen colonies which contained four queens were more efficient than the other tested colonies in the workers and drone brood rearing, while the single queen colonies (control) recorded the lowest value in all tested strains. The Italian strain occupied first place from the standpoint of workers brood rearing, followed by Carniolan, then the Carniolan hybrid strain comes in the last level while the Carniolan hybrid recorded the highest value in drone brood rearing. The multiple queen colonies recorded the highest amount of honey and pollen production, while the single queen colonies recorded the lowest value in all tested strains. Carniolan multiple queen colonies was occupied the first place in honey production followed by Italian multiple queen colonies then the Carniolan hybrid was occupied the last place. Total mean honey production in flow seasons may be arranged in descending order as clover, cotton and citrus flow season. That the multiple queen colonies which fed on pollen supplements indicated the highest amount of worker and drone brood, followed by multiple queen colonies which fed and pollen substitutes, while the single queen colonies which fed on sugar syrup (control) scored the lowest value. The pollen supplements feeding indicated the highest value of mean amounts of stored honey and pollen in the multiple queen colonies followed by multiple queen colonies which fed and pollen substitutes then the single 
queen colonies which fed on sugar syrup came on the last position. The Italian strain recorded the highest total amount of stored honey and pollen, while the Carniolan hybrid revealed the lowest total amounts. The three feeding types recorded the highest amount of stored honey and pollen in summer followed by spring and in descending order came fall then winter.

\section{Advisors' Committee}

Prof. Dr. Abd Elrahman Ahmed Donia (The late)

Prof. Dr. Osama Mohamed Nageb El-Ansary (The late)

Prof. Dr. Hedaya Hamza Karam

Dr. Magda Hassan Ali Salem

\section{Examiners' Committee}

Prof. Dr. Mohamed Bahgat Shawer

Prof. Dr. Hassan Mohammed Fathy

Dr. Magda Hassan Ali Salem

\section{Sc.}

\section{Maize, Zea mays L. Yield Losses Due to Insect Pest Infestation Hady Kamel Ibrahem}

This study aimed to assess three maize varieties yield losses caused by Sesamia critica, Ostrinia nubilalis and Fusarium moniliforme under insecticide treatment in El-Behiera governorate at different sawing dates using conventional and analytical methods. White corn recorded highest grain weight, $S$. creticae infestation reduced grains weight. Insecticide treatments decrease yield losses and white corn was the most susceptible variety for infestations. Analytical method was more accurate than the conventional method, sowing date effects on yield losses. Regression between yield losses and percent of borer's infestation was evaluated, it recorded a simple linear regression. Compensatory yield for absent or infested plants was estimated. Yellow corn recorded compensatory yield rate more than that for the white corn.

\section{Advisors Committee}

Prof. Dr: Mohamed Awad Al-Eryan

(Principal supervisor)

Dr: Amany Mostafa Abu-Shall

Dr: Hanaa Saleh Hussein

\author{
Examiners Committee \\ Prof. Dr. Mohamed Abd Elkader El-aw \\ Prof. Dr. Hanan Mohamed Ramadan \\ Prof. Dr: Mohamed Awad Al-Eryan \\ (Principal supervisor) \\ Dr: Amany Mostafa Abu-Shall
}

Ph. D.

\section{"Studies on the effect of Nanomaterials on some insect biology"}

\section{Fadwa Taha Mohamad Mohamadeen Ismail}

Musca domestica is a mechanical transport of several human pathogens. In search of environmentally friendly and effective pesticides, nanoparticles could be a new and good strategy for this reason. This study carried out to examine the efficacy of sliver $(\mathrm{Ag})$, zinc oxide $(\mathrm{ZnO})$, \& silica $(\mathrm{SiO})$ nanoparticles against Musca domestica larvae. Ag, ZnO NPs were synthesized by chemical method, the structural and morphological properties of the produced samples were characterized by SEM, TEM, \& UV-visible spectroscopy larvae were exposed to different concentrations of $\mathrm{Ag}, \mathrm{ZnO}$ and $\mathrm{SiO} \mathrm{NPs}$ by feeding and dipping method. Mortality rates obtained with $\mathrm{SiO}, \mathrm{ZnO}$ and $\mathrm{Ag}$ NPs at the highest concentration were 90 $\%, 86 \%$ and $60 \%$, respectively. After observation, the emerged adults couldn't mate because the reproductive genitalia severely affected, SEM images showed SiO NPs attach to the cuticle in different body parts of dead larvae.

Examiner's committee: Prof. Dr. Salwa El-Saeed Negm Prof. Dr. Madiha Mohamed Abdel- Hamid

Prof. Dr. Hussien Abdalla Rezk

\section{Advisors' Committee:}

Prof. Dr. Madiha Mohamed Abdel- Hamid

Prof. Dr. Eglal Mahmoud Assad Helal 
M. Sc.

\title{
Effect of some plant extract on stored product insect
}

\begin{abstract}
Mohammed Mohey El-Din Ahmed Farag
The effect of six plant essential oils against three stored grain insects, Sitophilus oryzae, Rhizopertha dominica and Tribolium castaneum were studied under laboratory conditions. The tested oils are namely, fennel oil (Foeniculum vulgare), caraway oil (Carum carvi), cinnamon oil (Cinnamomum verum), citronella oil (Cymbopogon winterianus), nutmeg oil (Myristica fragrans) and black cumin oil (Nigella sativa). The result showed that increasing of the oil concentration and exposure times significantly increased the mortality percentage.

Generally, the toxicity of essential oils at all tested concentrations increased with the increasing of exposure time. So, the results indicated that toxicity of all tested essential oil against the three stored grain insects at the high concentration was recorded high mortality faster than low concentration.

The tested essential oils significantly decreased the different haemocyte counts in tested insects, cinnamon oil markedly increased the haemocyte surface areas in the tested insects especially the surface area of oenocytoides in T. castaneum. The recorded results indicate that the essential oils of fennel, caraway, cinnamon and citronella could be applicable to the management of $S$. oryzae, $R$. dominica and $T$. castaneum adults.
\end{abstract}

Advisors Committee

Prof. Dr Abir Abd El Mageid Gad

Dr Mohammed Elsayed Tawfic

Dr Amany Abo-Shall

\section{Sc.}

\section{A Local Strain of Entomopathogenic Protozoans as a Biological Control Agent Against Certain Insect Pests}

\author{
Yasien Mohamed Gamal Yasien Zedan El Abed
}

Literaturely, attempts to use entomopathogenic protozoans for microbial control of stored product insect pests are few. Hence, to achieve a desired suppression in populations of such insect pests, actually, more studies are required on the following research points: protozoan natural infection rates in stored-product insects, protozoan disease incidence and epizootics, as well as the host ranges of candidate entomopathogenic protozoans. To provide biological suppression for the insect pests in storage, such research approaches should be invaded. Although insect pests of stored grains, seeds, and their products are among the most economically important pests in Egypt, there are no records on their naturally occurring entomopathogenic protozoans. Therefore, as a first step in casting the light on this field, the present work was carried out ,hopefully, (1) to document the Egyptian strain(s) of entomopathogenic protozoans originally isolated from certain stored grain insect pests; (2) to evaluate the potential of the isolated entomopathogen(s) as a possible microbial control agent(s) for certain storage insect pests (i.e., natural infection rates; pathogenicity and host range assays); (3) to mass-propagate the infective units, spores or oocysts, of one of such locally isolated protozoan entomopathogens. On achieving the above-mentioned research objectives, lots of 5-10 $\mathrm{kg}$ of storedcrushed maize grains and others of wheat, wheat flour, and rice were brought (in August and September 2015), from a private storehouse of stored grains in Koom-Hamada, El-Behera, Egypt, to the Insect Pathology Laboratory, Applied Entomology Department, Faculty of Agriculture (El-Shatby), Alexandria University, Alexandria, Egypt. All lots were infested primarily with the most abundant cosmopolitan insect pests of stored grains; namely, Cryptolestes sp. (=Laemophloeus sp.), Tribolium sp., Rhyzopertha dominica, Oryzaephilus surinamensis, Sitophilus sp., and Plodia interpunctella. All of the collected samples of the subject storage insect pests were maintained on crushed-maize grains and established as stock cultures under laboratory conditions of $25.3 \pm 3.8^{\circ} \mathrm{C}, 84.2 \pm 3.7 \%$ R.H., and photoperiods of $c a$. 12-14 hr. Naturally-occurring entomopathogenic protozoans were microscopically determined and infection rates were estimated for successive two years, 2016 and 2017. The haemocytometer and the micrometric lens were used to quantify and measure spore counts and dimensions per protozoan-infected cadaver, respectively. In order to mass propagate one of the isolated protozoan entomopathogens (the neogregarine, Mattesia sp.), single dose bioassays were adopted to determine the pathogenicity and host range for this Mattesia sp. 
The findings of the present study are summarized in the following points: The present study has documented, for the first time in Egypt, the natural occurrence of four entomopathogenic protozoans among five of the most abundant and damaging insect pests of stored grains or their products. These insect pests (L.turcicus, R.dominica, S.zeamais, T.castaneum, and P.interpunctella)were infesting lots of crushed-maize grains, wheat grains, and wheat flour. The morphological characteristics, including spore size, of the entomopathogen infective units, spores, of the isolated entomopathogenic protozoans, are closely fit the description to the following genera: Mattesia, Farinocystis, Adelina, and Nosema. The prevalence of these entomopathogens ranged between 9 and $89 \%$. This study seems to be the first report of Mattesia sp. on $S$. zeamais; Adelina sp. on L.turcicus or R.dominica, and the second report of Nosema sp. on R. dominica. The rate of natural infection by the neogregarine, Mattesia sp. (tentatively, $M$. dispora) was the highest in $L$. turcicus beetles $(89 \%)$ followed by that in P.interpunctella moths $(48 \%)$, larvae $(40 \%)$, and pupae $(32 \%)$; then in $S$. zeamais weevils (42\%), and $R$. dominica beetles with a low rate of infection $(9 \%)$. The microsporidian entomopathogen, Nosema sp., (tentatively, N. whitei)was naturally occurred in $11 \%$ of the examined adult cadavers of $R$. dominica. The coccidian entomopathogen, Adelina sp. was found, respectively, in $60 \%$ and $27 \%$ of larval and adult cadavers of T.castaneum; while the Adelina-natural infection rates in $R$. dominica and L. turcicus adult cadavers were $34 \%$ and $14 \%$, respectively. A high rate of natural infection with another neogregarine, Farinocystis sp. (tentatively, F.tribolii) has also been recorded in T. castaneum adult $(50 \%)$ or larval cadavers $(36 \%)$. Average yields of Mattesia spores (spore productivity) had varied from a minimum yield of $0.17 \times 10^{7}$ spores, for Laemophloeus turcicus adult, to a maximum yield of $7.46 \times 10^{7}$ spores, for Plodia interpunctella larva. Comparatively, the highest increase in Mattesia spore yield, recorded from P.interpunctella larva $\left(7.46 \times 10^{7}\right.$ spores $)$ over the lowest one, estimated for L. turcicus adult $\left(0.17 \times 10^{7}\right.$ spores), was nearly 44-fold; while the increase in Mattesia spore yields, which have been calculated for the other hosts (P.interpunctella pupa or moth; Galleria mellonella larva; Rhyzopertha dominica adult; Sitophilus zeamais), over that estimated for L.turcicus adult, were significantly less than 10-fold (6-9 folds). On basis of a one gramme insect host infected with the entomopathogen, Mattesia sp., small stored-grain insect hosts (e.g., L.turcicus , S.zeamais, and R.dominica) seem to achieve Mattesia-spore yields (spore productivity) many times more than larger ones (e.g., P.interpunctella). The increase in spore yields over that used for the inoculum, based on an average of 25 P.interpunctella larvae per bioassay container, was ca. 2-to 31-fold. Values of the median lethal time $\left(\mathrm{LT}_{50}\right)$ and concentration $\left(\mathrm{LC}_{50}\right)$ were estimated in order to obtain more information on the lethal infection of the present Mattesia isolate towards the chosen host, P. interpunctella larvae of 7-10-day-old, fed on crushed-maize grain contaminated with different Mattesia doses ranging from 0.01 to 0.16 gm powdered cadavers of L. turcicus-Mattesia-infected adults (contained $\mathrm{ca}$. $1.5 \times 10^{8}$ to $24 \times 10^{8}$ Mattesia spores per $10 \mathrm{gm}$ crushed-maize grain). The results reveal that the Indianmeal moth, P.interpunctella could serve as a potential host for mass propagating the isolated entomopathogenic protozoan, Mattesia sp. Besides Mattesia-larval mortality, survivors of Mattesia infection suffer deformities and noticeable undersized pupae or adults, as compared to the control ones. Also, many copulated moths (ca.46\%) were unable to become separated after copulation until they had died. Bioassay of siftings, obtained from $L$. turcicus-protozoan-infected stock cultures, has been carried out in order to emphasize the suppressive potent role of such protozoan entomopathogens in long-term storage. With the highest test concentration of the studied siftings (10\%), mortality responses due to Mattesia infection were ranged from 13 to 68\% 14-169 days post-treatment; whereas the corresponding figures for Adelina infection were $7-42 \%$. The present study may recommend the following points: from the microbial control standpoint, a periodic isolation for the local strain(s) of the entomopathogenic protozoans associated with stored-grain insect pests is important for monitoring such promising biological control agents. Consequently, Egypt could possess its own arsenal of local microbial control agents (i.e., entomopathogenic protozoans or others) to suppress, through natural or applied measures, the populations of insect pests in storage.

Supervisors' Committee Hedaya Hamza Karam

Ahlam Ahmad Alfazairy

Hanan Mohamed Ramadan
Examiners' Committee

Monir Mohamed Mohamed El Hussieni

Esmat Mohamed Hegazi

Hedaya Hamza Karam 
M. Sc.

\title{
Studies on Insect Pests of Some Ornamental Plants
}

\author{
Mohamad Ali Ahmed Abou-Ghonem
}

A general survey of insect pests infesting some ornamental shrubs and their natural enemies at Alexandria Governorate, was carried out in Alexandria gardens during two successive years, 2013 and 2014, illustrated the presence of 32 insect species belonging to two orders (Hemiptera and Lepidoptera) and 10 families on 20 plant species in 12 locations. Population fluctuations of 3 aphid species and 2 mealybug species developmental stages were followed in this study. Developmental periods of Aphis nerii reared on Nerium oleander leaves and Planococcus citri reared on potato tubers were followed at different degrees of temperatures and relative humitities. Increasing temperature, significantly decreased the duration of $A$. nerii $3^{\text {rd }}$ larval instar, mean longevity, total life cycle and the mean number of deposited larvae per female. The first, second and third instar duration, longevity and total life cycle of $P$. citri decreased significantly as the temperature increased. On the other hand, increasing temperature resulted in increasing number of deposited eggs per P. citri female. biological study were conducted, for the first time in Egypt, on the blue butterfly, Chilades pandava (Lepidoptera: Lycaenidae: Polyommatinae. Polyommatini) observed attacking cycad palm tree Cycas spp. (Family: Cycadophyta). Morphological study of egg, larva and pupa stage was carried out using SEM photographes.

\section{Advisors' Committee:}

Eglal Mahmoud Assad Helal

Hanan Mohamed Ramadan

Mohamed Elsayed Tawfeek

Amany Mostafa Abou-Shall

\author{
Exameners' Commitee: \\ Eglal Mahmoud Assad Helal \\ Hedaya Hamza Karam \\ Mohamed Abd El-Kader Mansour \\ Mohamed Elsayed Tawfeek
}

\section{Vegetable crops}

\section{Ph. D.}

\section{Response of Growth and Exportable Yield of Sweet Pepper Grown in Calcareous Soil under Green House to Water Regime, Pruning and Potassium Silicate}

\section{Hamada Mohamed Kotb Hassan}

Two greenhouse experiments were carried out at Army Farm, at El-Amria region, Alexandria, Egypt, during the two seasons of 2016-2017 and 2017-2018, to studying the effect of water regime, pruning system and potassium silicate on the growth, fruit yield and physiological responses of sweet pepper plants. The results showed that sweet pepper plants that irrigated at of $30 \%$ of depletion ratio and pruned by Holland system with left 2 stems per plant and spraying the growing plants with the highest concentration of potassium silicate (1000 mg 1-1) might be considered as an appropriate treatment combination for achieving higher exportable and total fruits yield as well as saving irrigation water up to $60 \%$ and maximum water use efficiency of sweet pepper plants.

\section{Advisors committee}

Prof. Dr. Hegazi Hassan Hegazi

Prof. Dr. Ibrahium Mohamed Ghoneim

Prof. Dr. Mostafa Nabawy Feleafel (Supervisor)
Examiners committee

Prof. Dr. Farouk Abd El-Salam El-Aidy

Prof. Dr. Hegazi Hassan Hegazi

Prof. Dr. Mostafa Nabawy Feleafel (Supervisor)

Prof. Dr. Melad Helmy Zaky 
M. Sc.

\section{Effects of Planting Dates Plastic Mulch Color's and Foliar Application of Salicylic Acid on Growth and Productivity of Sweet Potato (Ipomoea batatas (L.) Lam.). Mohamed Hesham Mohamed Abd Al-Moniem Khadr}

In a view of the obtained and discussed results, of the present study, concluded that the application of the different color's mulch and spraying with the salicylic acid at 100 or 200 p.p.m., was beneficial to stimulating the vegetative growth characters of the sweet potato plants and the yield potential, quality characteristics, as well as, most of the plant leaf and the root storage tubers chemical constituents of the sweet potato plants. However, it was conclude also that color's mulch, is preferred, especially during the cool seasons (autumn and winter) to heat the soil and can improve the growth of the sweet potato plants when growing under the cool conditions (late of September and early of November) under the prevailing environmental condition of Alexandria province and other similar regions, and optimize yield of the sweet potato as well as, to attain market quality standards.

The results, indicated that mulching in all the colors used and the salicylic acid (S.A.) concentrations especially at 200 p.p.m. and their interaction treatments showed an important role in enhancing the vegetative growth characters, the yield and its components and the chemical compositions of the sweet potato plants. The use of mulching and the salicylic acid (S.A.) was beneficial especially in the cool seasons (autumn and winter).

\section{Advisors Committee}

Prof. Dr. Moukhtar Mansour Kamel Doss.

Prof. Dr. Mohamed Ahmed Abdel-Fattah.

Dr. Doaa Yehia El Dien Hammad.

\section{Examiners Committee}

Prof. Dr. Moukhtar Mansour melKa Doss.

Prof. Dr. Younis Bayumy Ahmed El-Waraky.

Dr. Doaa Yehia El Dien Hammad.

Dr. Shaimaa Mohamed Hassan Ragab.

\section{Soil and Water Sciences}

\section{Sc.}

\section{Physiological Response and Nutrient Uptake of Different Tomato Cultivars Grown in Hydroponic Culture under Salinity Stress}

\section{Aly Saied Mostafa}

The negative effects of salinity on growth and productivity of plants are osmotic effect that results from the relatively high solute concentrations in the growing medium, specific ion toxicity resulting from high $\mathrm{Na}^{+}$ and $\mathrm{Cl}^{-}$ion concentrations that are inimical to plants, nutritional imbalance, and production of reactive oxygen species (ROS), which disturbs photosynthesis and physiology of the plants. The most common effect of increasing salinity levels on hydroponically grown tomato cultivars is the reduction of growth in most genotypes. Cult.1077 recorded increasing in growth parameters under 50 and $100 \mathrm{mM} \mathrm{NaCl}$. Na concentrations of shoots and roots in most genotypes increased by increasing salinity in hydroponic media. While $\mathrm{N}, \mathrm{P}$ and $\mathrm{K}^{+}$concentration decreased with $\mathrm{NaCl}$ application to Hoagland solution. $\mathrm{Na}^{+} / \mathrm{K}^{+}$ratio of all genotypes increased significantly with increasing $\mathrm{NaCl}$ levels in the hydroponic solution. In contrast, $\mathrm{Na}^{+}, \mathrm{N}$, $\mathrm{P}$ and $\mathrm{K}^{+}$concentration increased in Cult.1077 with $\mathrm{NaCl}$ application to Hoagland solution. The uptakes of $\mathrm{N}$, $\mathrm{P}$ and $\mathrm{K}^{+}$in shoots and roots $\left(\mathrm{mg} \mathrm{g}^{-1}\right)$ increased up to $100 \mathrm{mM}$. Enzyme activity such as; Catalase (CAT) and Peroxidase (POX) of hydroponic grown shoots and roots increased significantly with increasing salinity levels in all genotypes. Activity of POX $\left(\mathrm{U} \mathrm{g} \mathrm{g}^{-1}\right)$ in Cult.1077 increased by $(209,637,676$ and $691 \%)$ in shoots and $(336.02,571.5,692.47$ and $677.41 \%)$ in roots with 50, 100, 150 and $200 \mathrm{mM}$, respectively. Statistical analysis reported significant variations among levels of salinity and species and each other, at 5\%.Thus, it can be concluded that I) Cultivar 1077 is proven as a potential saline tolerant variety achieving the goal. II) Cultivar 380 is moderate. And III) Cultivar 010 is more sensitive to salinity stress, relative to studied cultivars. The cultivar 1077 exhibited shoot ion-independent tolerance (the maintenance of growth, water uptake, and nutrients independent of the extent of $\mathrm{Na}^{+}$or $\mathrm{Cl}^{-}$accumulation in the shoot. In addition, mild salinity seemed to stimulate its growth and biological activity. The root tips could be considered a good indicator for screening and determining the plant salt tolerance. The addition of $\mathrm{Ca}-\mathrm{Mg}$ - and $\mathrm{K}$-Citrate to 
Cult.010 improved the growth and nutrients concentration. In contrast, application of Ca-, Mg- and $\mathrm{K}-\mathrm{Citrate}$ by $100 \%$ reduced the growth and nutrients concentration to Cult.1077. While a significant increase in growth and nutrients concentration were observed with 50\% of Ca-Mg- and K-Citrate. Finally, it could be concluded that salinity stress reduced the uptakes of water and nutrients, make a toxicity for plant and increased the $\mathrm{H}_{2} \mathrm{O}_{2}$ in plant cellular.

Examiner's committee: Prof. Dr. Mohamed Safwat Shams

Prof. Dr. Fatma Kamal Sherif

Prof. Dr. Ahmed Mohamed Mahdy
Advisors' Committee:

Prof. Dr. Fatma Kamal Sherif

Prof. Dr. Ramzy M. R. Hedia

\section{Sc.}

\section{Improving Efficiency of Nitrogen Fertilization Using ${ }^{15} \mathrm{~N}$ Mohammed Mohammed Elsoufy Amin}

The objective of the present study was to use alternative $\mathrm{N}$ sources (Organic) to minimize $\mathrm{N}$ losses with improving fertilization practices using ${ }^{15} \mathrm{~N}$ tracer technique.

Three Field experiments were conducted on virgin sand soil under drip irrigation system using wheat, sesame and maize as tested crops. Tested crops were fertilized with ${ }^{15} \mathrm{~N}$ labeled ammonium sulfate fertilizer, commercial compost locally manufactured in Egypt and artificial compost prepared by author, which are completely (100\%) mineral and organic; and 50\%:50\% (mineral : organic).

The results revealed that dry weights and $\mathrm{N}$ uptake of straw, roots and seeds of wheat increased significantly with addition of $50 \%$ artificial compost (CE) $+50 \%$ mineral fertilizer (MF) comparing with all treatments. Similar trends were noticed with Sesame and Maize.

For all tested crops, Nitrogen derived from fertilizer (Ndff) and fertilizer use efficiency (\% FUE) were increased significantly by the addition of organic and mineral fertilizer but the data of Nitrogen derived from organic manure (\%Ndfo) didn't reflect big significant differences.

It could be concluded that, the application of organic and mineral fertilizer at an appropriate rate is crucial to maximize the productivity of tested crops. In particular, increased immobilization by organic amendment application in the early stage and the subsequent gradual re-mineralization allowed plants to utilize inorganic$\mathrm{N}$ more efficiently. Use of ${ }^{15} \mathrm{~N}$ isotope dilution technique gave us the chance to follow up the proportions of nitrogen derived to tested crops from the different sources accurately.

Advisors' Committee

Prof. Dr. Samir Ibraheem Ghabour

Dr. Dalia Mohamed Elsoufy

Prof. Dr. Soliman Mohamed Soliman

\author{
Advisors' Committee \\ Prof. Dr.Yehia Galal Mohamed Galal \\ Prof. Dr. Sawsan Ahmed Saif Elyazal \\ Prof. Dr. Soliman Mohamed Soliman Professor of \\ Prof. Dr. Samir Ibraheem Ghabour
}

\section{Sc.}

\section{Removal of Cadmium and Zinc Contaminants from Industrial Waste Water by Using Nano Particles of Moringa Seed Waste}

\section{Basma Mahmoud Ebrhaim Shaker}

The First order and power function model were statistically superior to the other models tested in(Cadmium and Zinc) adsorption by nanoscale moringa seed waste (nMSW). The Results of the adsorption experiments showed that(nMSW) was effective in $\mathrm{Cd}(\mathrm{II})$ removal and its maximum adsorption was 10 times higher than that of (bMSW) and effective in $\mathrm{Zn}(\mathrm{II})$ removal and its maximum adsorption was 7 times higher than that of (bMSW). The highest efficiency of $\mathrm{Cd}$ or $\mathrm{Zn}$ removal was at temperature of $318 \mathrm{~K}$ and $\mathrm{pH} 9$. Biosorption of $\mathrm{Cd}$ or $\mathrm{Zn}$ increases rapidly with increasing adsorbent dose of nMSW from 0.02 to $0.10 \mathrm{~g}$.

\author{
Advisor's Committee: \\ Dr. Elsayed Ahmed Elkhatib \\ Dr. Ahmed Mohamed Mahdy \\ Dr. Mohamed Lotfy Moharem
}

\author{
Examiners Committee: \\ Dr. Maher Gorgy Nessim \\ Dr. Elsayed Ahmed Elkhatib \\ Dr. Fatma Kamal Sherif \\ Dr. Ahmed Mohamed Mahdy
}


M. Sc.

\title{
Ameliorating Salinity Tolerance of Cucumber Plants with water Treatments Residuals Nanoparticles
}

\author{
Mona Hassan Saleh Ahmed
}

Salinity is one of the major abiotic factors that limit plant growth and productivity in many regions of the world. Therefore, many trails and approaches have been attempted to mitigate the well-known negative effects of salinity on plant growth and production. The objectives of this study were to characterize the physical and chemical properties of nanoscale water treatment residuals (nWTRs), and to evaluate the impact of the nWTR and salinity stress on physiological parameters such as germination, root growth, chlorophyll concentration index, enzyme content such as catalase and peroxidase, soluble protein, and in plant. Finally, it can be said that the nWTRs is improved material for the growth of cucumber plants under saline conditions.

\author{
Examiner's committee \\ Prof. Dr. Maher Gorgy Nessim \\ Prof. Dr. Fatma Kamal Sherif \\ Prof. Dr. Ahmed Mohamed Mahdy \\ Prof. Dr. Ahmed Farid Saad
}

\author{
Advisors' Committee: \\ Prof. Dr. Elsayed Ahmed Elkhatib \\ Prof. Dr. Fatma Kamal Sherif \\ Prof. Dr. Ahmed Mohamed Mahdy
}

\section{Dairy Science and Technology}

M. Sc.

\section{The Influence of Some Stabilizers on the Textural Properties of Spreadable Processed Cheese}

\section{Ali Salama Ramadan Elshanshory}

This study concluded that the addition of stabilizers in the manufacture of processed cheese can positively support the change in the shape of the final product. In addition, the use of stabilizers and mixtures stabilizers to processed cheeses modifies structural and rheological properties (hardness, adhesiveness, cohesiveness, springiness, chewiness) of the final product and the effect depends on the type of stabilizer or mixtures stabilizers. The total number of bacteria in different types of cheese ranged from 230-260 cfu / gm, which falls within the acceptable range in previous studies of Egyptian legation.

In conclusion, it is recommended to use either of the two previous combinations (Car or Xan) as stabilizer to produce simulations of the economically feasible processed cheese containing $6 \%$ protein without any negative effects on both the physical and chemical - rheological - microbiological and sensory properties.

Advisors Committee:

Prof. Dr. Nahed Elsayed Soliman

Prof. Dr. Eman Abd Elhamid Eldakhakhny

Dr. Nassra Ali Dabour
Examiners Committee:

Prof. Dr. Mahmoud Samy elghannam

Prof. Dr. Sherif Mesbah Shamsia

Prof. Dr. Eman Abd Elhamid Eldakhakhny

Dr. Nassra Ali Dabour 
Ph. D.

\title{
Some Health Promoting Activities of Buttermilk
}

\author{
Heba-tullah Mohamed Abd-Allah Mohamed Abd-Elhaleem
}

\begin{abstract}
The present study concluded that buttermilk could successfully be used as an additional source of milk solids in yoghourt manufacture. Partial substitution, up to 50\%, of skimmed milk with buttermilk powder did not seriously affect chemical, textural, sensorial and microbiological quality of yoghurt. The potential hypocholesterolemic ability of strain Enterococcus faecium FFNL-12 is promising candidate to be used for the preparation of probiotic supplements or as adjunct culture in the preparation of fermented dairy product. In vivo results indicated that this strain did not accompany with any health complications or toxic effects. MFGM fraction as well as E. faecium FFNL-12/buttermilk combination had effective effect to reduce serum lipids and glucose levels to the normal range, potential antioxidant activity and ability to improve liver and heart functions.
\end{abstract}

\section{Advisors Committee:}

Prof. Dr. Ehab Essa Kheadr

Prof. Dr. Mostafa Abd-Elmoneam Zedan

Prof. Dr. Mohamed Gamal El-deen El-Zeiny

Dr. Khaled El-Saadany
Examiners Committee:

Prof. Dr. Hassan Noureldin Hassan Ibrahim

Prof. Dr. Ehab Essa Kheadr

Prof. Dr. Aisha Mohamed El-Attar

\section{Economics \& Agribusiness}

\section{Ph. D.}

\section{The Effect of Climate Changes on Economic Variables of Some Strategic Crops in Egypt}

\section{Hanan Shawky Mohamed Khalil Ibraheem}

The objective of this study is to recognize what 1s The Effect of Climate Changes on Economic Variables of Some Strategic Crops in Egypt.

The present study contains four main chapters the first chapter includes the study introduction. the second chapter includes former studies and the theoretical and analytical frame by showing the main concepts of the study besides the best methods. analytical forms used in achieving the study goals also. the third chapter is focused on measuring directions of climate change and its effect on strategic crops in Egypt. the fourth chapter deals with analyzing the risks and the farmers opinions towards climate change in the study sample.

\author{
Advisors Committee \\ Prof. Dr. Sherin Sherif \\ Prof. Dr. El-Hussein Abd El-Latif \\ Dr. Sameh Mohamed Hassan Shehab
}

\section{Examiners Committee}

Prof. Dr. Mohamed Salah El-Deen El-Gendy

Pro. Dr. Mohamed Abd El-Wahab Abo nahol

Prof. Dr. El-Hussein Abd El-Latif El-Seify

Dr. Sameh Mohamed Hassan Shehab

Ph. D.

\section{The Economics of Production and Marketing of Egyptian Cotton in El-Beheira Governorate}

\begin{abstract}
Ahmed Mahmoud Mohamed Shama
The study examined the economics of production and marketing of Egyptian cotton. The problem of the study is the decrease in the area under Egyptian cotton and its productivity. The study aims to identify the most important problems facing Egyptian cotton production and marketing, and used descriptive and quantitative economic analysis.

The study included 4 chapters: the first chapter studied the theoretical and analytical frame, the second chapter studied the economic indicators of cotton crop in Egypt, the third chapter studied competitiveness
\end{abstract}


indicators of Egyptian cotton, and the forth chapter studied the economic indicators and problems of production and marketing of cotton in the study samples. The study recommended that the government should market the crop, provide special support to cotton producers to encourage them to farm it, and establish a cotton price stabilization fund in order to protect the Egyptian cotton market.

\section{Examiner .s Committee}

Prof. Dr. El-Hussein Abd El-Latif El-Seify

Prof. Dr. Saad Zaghlool Soliman

Prof. Dr. Olfat Aly Melouk

Prof . Dr. Amr Abdel Hamied Refaat Professor of

\section{Supervisors Committee}

Prof. Dr. ELSayed Mahmoud El Sharkawy

Prof. Dr. El-Hussein Abd El-Latif El-Seify

Prof. Dr. Saad Zaghlool Soliman

Ph. D.

\title{
Developing Egyptian Trade to some of the Nile Basin Countries
}

\section{Mohamed Aly El-Sayed Aly}

Today, the world is living with many variables that require developing countries to reconsider their development path. It is difficult for a country to achieve its development requirements by its own efforts without resorting to other countries to share and share common benefits. In addition, these successive global variables are not risk free. The impact of these risks by increasing cooperation between countries, especially at the regional level. In the context of the Egyptian approach to support and activate relations with the countries of the African continent, the Nile Basin Initiative, an international agreement signed between the nine Nile Basin countries in Tanzania and joined by Eritrea as an observer in February 1999 with the aim of strengthening regional cooperation between these countries. The agricultural sector is one of the most important sectors of Egypt where Plays a big role in the national economy is the locomotive that can achieve self-sufficiency of food if the full attention of the Egyptian government in all areas of agriculture, the first water and pesticides and / modern methods of agriculture as well as attention to exports Agriculture in African countries in general and in the Nile Basin countries in particular.

\author{
Advisors Committee \\ Prof .Dr. Essam A. Abou El-Wafa \\ Prof .Dr. Olivia El-Sayed Saleh \\ Prof .Dr. El-Hussein Abd El-Latif El-Seify
}

\author{
Examiners Committee \\ Prof .Dr. Olivia El-Sayed Saleh \\ Prof .Dr. Mostafa Mohamed Mohamed El-Sadany \\ Prof .Dr. El-Hussein Abd El-Latif El-Seify \\ Prof. Dr. Waheed Mohamed El-Bolony
}

\section{Agronomy}

\section{Ph. D.}

\section{Genetic Diversity and Gene(s) Detection for Drought Tolerance in Wheat}

\section{Doaa Ahmed Mohamed Hamza}

\begin{abstract}
The present investigation emphasized that wheat genotypes enjoying the ability to increase their osmotic potential and maintain adequate grain filling rate for a longer duration will produce more grain yield under drought stress conditions. Water productivity was, in general, higher under drought stress treatment due to lower amount of irrigation water applied and the ability of most wheat genotypes to tolerate stress and give acceptable grain yield. The use of RCI and PCI were more effective in determining the resilience and productivity of divergent wheat genotypes under drought conditions compared to individual, generally applied, indices. Moreover, applying those two indices may determine the suitability of wheat genotypes for cultivation in drought-prone areas for their ability to produce an acceptable yield under water deficit conditions or their use in breeding programs for developing cultivars with both high resilience and productivity.
\end{abstract}

\section{Examiners' Committee}

Prof. Dr. Mohamed Abdel-Salam Rashed

Prof. Dr. Samy Reda Saber Sabry

Prof. Dr. Mohamed Nagiub Barakat

Prof. Dr. Ali Issa Nawar

\author{
Advisors' Committee \\ Prof. Dr. Mohamed Nagiub Barakat \\ Prof. Dr. Ali Issa Nawar \\ Prof. Dr. Sanaa Ibrahim Mohamed Milad \\ Prof. Dr. Anwar Abd El-Khalek Ageez
}


M. Sc.

\title{
Biodiversity and Identification of a DNA Marker Linked to Bolting Gene (s) in Egyptian Sugar Beet (Beta vulgaris L.) Lines
}

\author{
Asmaa Youssef Mekhemer Farghaly
}

\begin{abstract}
The results obtained by the molecular markers analysis, showed that, it is in a complete conformity and agreement, with our previous results, obtained by the agro-morphological traits analysis. The genetic purity was assessed within the populations and the result showed that the population EG27. 2016 recorded higher purity using SSR markers while the sugar beet population EG26.2014 gave the lower purity using ISSR markers, and the Correlation between agronomic traits and molecular markers showed that a significant correlation among either molecular markers and agronomic dendrograms. High significant and correlation among molecular markers were observed. While the second experiment results identified bolting gene in sugar beet using SSR markers, Out of 10 SSR primers used in this study, only primer BVV15 generated the polymorphic fragments at $200 \mathrm{bp}$, which were present only in bolting bulk and were missing in non-bolting bulk in all sugar beet populations.
\end{abstract}

Examiners' Committee

Prof. Dr.Mohamed M. El Ashri

Prof. Dr. Ali Issa Nawar

Prof. Dr. Mohamed N. Barakat

Prof. Dr. Nabawya Saleh Abdo Ghura

\section{Home Economics}

Advisors' Committee

Prof. Dr. Mohamed N. Barakat

Prof. Dr. Sanaa I. M. Milad

Prof. Dr. Nabawya Saleh Abdo Ghura

\section{Sc.}

\section{Evaluation of the Nutritional Value and Organoleptic Properties of Some Foods Containing Plant Milk}

\author{
Ayah Mohamed Tawfik El-Hossainy
}

The consumption of vegan milk has been increased due to the absence of cholesterol and lactose. Also, in recent years, plant sources (cereals and legumes) are accepted as functional foods and nutraceutical.

The main aim of the study was focused on nutritional value and sensory properties of vegan milk and its products. The present study described protocols to manufacture many products from some vegan milks (prepared from rice, coconut and almond).

Concerning vegan milks, the study found that almond milk appeared to have the highest protein content ( $6.10 \%$ ) while coconut milk had the lowest content $(2.30 \%)$. Also, almond milk showed the highest content of $\mathrm{Ca}, \mathrm{Mg}, \mathrm{P}$ and $\mathrm{Zn}$. Cow milk which treated at $70^{\circ} \mathrm{C}$ and stored for 3 days was preferred in all sensory characteristics in most cases compared with vegan milk. Scores of taste of cow and coconut milk at $70{ }^{\circ} \mathrm{C}$ stored for 3 days were close to each other.

Blending different amounts of strawberry rice fermented milk with coconut milk increased $\mathrm{PH}$ values of the resultant milk. most of the sensory characteristics of fresh strawberry fermented milk using $50 \%$ brown rice milk $+50 \%$ coconut milk were better relative to odour, colour, flavour, and acceptability as well as total score.

Sensory characteristics of fresh cheese prepared by using $70 \%$ rice $+30 \%$ almond was better relative to odour, taste, and colour as well as overall while acceptability cheese done with $100 \%$ rice stored for 14 day had significantly the lowest scores for odour, taste, colour and overall acceptability.

\section{Advisors Committee}

Prof. Dr. Samir Mohammed Ahmed

Prof. Dr. Soheir Mohamed Fouad Nour

Prof. Dr. Nasser Ibrahim Abdo Elnaga

Prof. Dr. Ehab Essa Kheadr

\section{Examiners Committee}

Prof. Dr. Mohamed Salah El-Deen El-Gendy

Pro. Dr. Mohamed Abd El-Wahab Abo nahol

Prof. Dr. El-Hussein Abd El-Latif El-Seify

Dr. Sameh Mohamed Hassan Shehab 
Ph. D.

\title{
Comparing the Nutritional and Healthy Value of Ghee "Samna" with Some Oils and Fats
}

\author{
Amira Abd Elhady Awad Hussein
}

\begin{abstract}
Ghee in Egypt is called "samna baladi". It is commonly made from buffalo milk and sometimes from cow milk. Ghee is a product that is made by indigenous methods in many countries around the world. Egyptian ghee had the highest saponification value, and highest content of Vitamins A. Plant ghee had the highest in the depth of the yellow color, smoke point, peroxide value and stability. While sheep fat characterized by the highest value of refractive index, $\beta$-carotene, chlorophyll and vitamins ( $E$ and $D)$ contents. Morta is a reach source of protein, and it has higher cholesterol content than samna.
\end{abstract}

\section{$\underline{\text { Advisors Committee }}$}

Prof. Dr. Soheir Mohamed Fouad Nour

Prof. Dr. Khadiga Nasser El-Dine Mohamed

Prof. Dr. Azaa Abd Alla Ahmed

\section{Examiners Committee}

Prof. Dr. Soheir Mohamed Fouad Nour

Prof. Dr. Khadiga Nasser El-Dine Mohamed

Prof. Dr. Awatef Ibrahim Ismaeil

Prof. Dr. Sameh Ali Mohamed Awad

\section{Animal and Fish Production}

Ph. D.

\section{Effect of Phytoestrogens on Reproductive Performance and Heamato- Biochemical Parameters in Male Rabbits}

\author{
Marwa Abd Elghany Abo El-Soud
}

The present study aimed to investigate the effects of different levels ( 5 and $20 \mathrm{mg} / \mathrm{kg} \mathrm{BW}$ ) of soybean isoflavones (Genistein and daidzein) and the source of dietary phytoestrogens (soybean isoflavones and flaxseed lignans) on reproductive performance, hemato-biochemical parameters and antioxidant enzyme activities in adult male rabbits. The present study was carried out at the Physiology Rabbit Research Laboratory. Animal and Fish production Department, Faculty of Agriculture, Alexandria University, Egypt, during winter and spring seasons (from January to April 2016). Thirty-five sexually mature V-line rabbit bucks 6-7 months old (average initial body weight $3.000 \pm 0.06 \mathrm{~kg}$ ) at the beginning of the experiment were used. The results of this study indicated that the low dose of soybean isoflavones supplement was enough to induce hormonal imbalance and impair libido, spermatogenesis and fertility of adult male rabbits, and therefore the positive effects observed for the high dose of isoflavones supplement on antioxidant activity could not be considered beneficial for adult males during their fertility period. Consumption of dietary soybean isoflavones or linseed lignans by adult male rabbits caused obvious alterations in libido and testis functions leading to inadequate steroidgenesis and spermatogenesis

\section{Advisors Committee}

Prof. Dr. Gamal El-Din Abd El-Rehim Hassan

Prof. Dr. Adel N. M. Nour El-Din

Prof. Dr. Kamel Ibrahim Kamel

Dr. Nesrein Mohamed Hashem

\section{Examiners Committee}

Prof. Dr. Ibrahim Saad EL

Prof. Dr. Mokhtar Ibrahim Yousef

Prof. Dr. Gamal El-Din Abd El-Rehim Hassan

Dr. Nesrein Mohamed Hashem 